\title{
Çevrimiçi Cihaz Kullanımındaki Akış Deneyiminin Tüketicilerin Satın Alma Kararları Üzerindeki Etkisi ${ }^{1}$
}

\author{
Araştırma Makalesi/Research Article
}

\author{
Cem Ufuk BAYTAR \\ MYO, İşletme Yönetimi Programı, Beykent Üniversitesi, İstanbul, Türkiye \\ ufukbaytar@beykent.edu.tr \\ (Geliş/Received:18.08.2019; Kabul/Accepted:26.01.2020) \\ DOI: $10.17671 /$ gazibtd. 606067
}

\begin{abstract}
Özet - Tüketicilerin çevrimiçi alışveriş yaparken farklı elektronik cihazları (masaüstü bilgisayar, dizüstü bilgisayar, akıllı telefon, tablet) kullanarak alışverişlerini tamamlamalarına neden olan unsurların araştırılması hedefi çalışmanın çıkış noktası olmuştur. Bu çalışmada çevrimiçi alışverişte bilgisayar ya da mobil cihazların kullanılması sırasında müşterilerin yaşadıkları akış deneyiminin memnuniyet ve satın alma kararlarına etkisi var mıdır? Sorusu araştırma problemini oluşturmaktadır. Tanımlayıcı araştırma yöntemi benimsenerek modelde bulunan değișkenlerle ilgili doğru tanımların yapılması hedeflenmiştir. Bu hedefe yönelik birincil verilerin toplanması için anket yöntemi uygulanmıştır. Tesadüfi olmayan örnekleme yöntemlerinden kolayda örnekleme kullanılmış olup bu nedenle örneklemin büyüklüğü geniş tutulmuştur. Araştırma Eylül 2016 ve Mayıs 2017 arasındaki dönemde çevrimiçi satın alma yapan ve İstanbul'da ikamet eden 18 yaş ve üzerindeki tüketiciler ile yapılmıștır. Araştırmanın sonuçlarına göre, cihazlardan algılanan kullanım kolaylığının ve algılanan faydanın akış deneyimi üzerinde olumlu etkisinin olduğu ortaya çıkmıştır. Akış deneyiminin memnuniyet üzerinde olumlu etkisi belirlenmiştir. Bilgi kalitesi ve kanal kalitesi değişkenlerinin düzenleyici rolleri olduğu anlaşılmıştır. Çevrimiçi cihazlardaki müşteri memnuniyetinin satın alma kararları üzerinde olumlu etkisinin olduğu ortaya konmuştur.
\end{abstract}

\section{The Effect Of Flow Experience In Using Online Devices On Purchasing Decisions Of Customers}

\begin{abstract}
The goal of investigating the elements that cause consumers to complete their purchases using different electronic devices (desktop, laptop, smartphone, tablet) when shopping online is the starting point of the study. The question of that does customers' flow experience of shopping online by using computers or mobile devices have an impact on the satisfaction and purchasing decisions? constitutes the research problem. By adopting an descriptive research method, it is aimed to make correct definitions of the variables in the model. A survey method has been applied for the collection of primary data for this goal. The easy sampling method of non-random sampling methods was used and therefore the size of the sample was kept wide. The questionaire has been applied to online shoppers in İstanbul who are above 18 at the period between September 2016 and May 2017. According to the search results, it has been found that perceived ease of use and perceived usefulness have positive effects on flow experience. It has been determined that flow experience affects customer satisfaction positively. It has been understood that Information quality and channel quality variables have their moderator roles. It has been revealed that customer satisfaction from all device types has positive effects on purchasing decisions.
\end{abstract}

Keywords - Online Shopping, Flow Experience, E-commerce, Customer Satisfaction, Purchasing Decision

\footnotetext{
$1 \mathrm{Bu}$ çalışma, Cem Ufuk Baytar'ın Beykent Üniversitesi, Sosyal Bilimler Enstitüsü’nde Prof. Dr. Cemal Yükselen’in tez danışmanlığında gerçekleştirilen “Tüketicilerin Çevrimiçi Alışveriş Kanallarındaki Akış Deneyimlerinin Memnuniyet ve Satın Alma Kararlarına Etkisi, Bilgi ve Kanal Kalitesinin Rolü” başlıklı doktora tezi (28.02.2018, İstanbul) çalışmasından türetilmiştir.
} 


\section{GİRIŞ (INTRODUCTION)}

E-ticaret uygulamalarındaki artışın nedenleri arasında küreselleşme olgusu yer almaktadır. Küreselleşme mal, hizmet, insan, bilgi ve fikirlerin tüm dünya ülkelerinde, sınır ve engel tanımadan serbestçe dolaşması olgusu ve ülke resmi makamlarının da bu olguyu destekleme yönündeki eğilimlerini açılayan bir kavramdır. Diğer bir deyişle, küreselleşme, ekonomik faaliyet, bilgi, teknoloji ve fikirlerin dünyaya engelsiz yayılması ve bu yayılmayı destekleyen politik, yasal ve kültürel düzenlemeler olarak tanımlanmaktadır [1].

E-ticaret, işletme ile iş ortakları (müşteri, tedarikçi vb.) arasında elektronik ortam (internet, mobil iletișim ağları) aracıllı̆̆ ile gerçekleştirilen ticari veya ticari olmayan işlemlerdir [2].

Çevrimiçi alışveriş, internet üzerinden web tarayıcısının kullanılmasıyla satıcının ürün ve hizmetlerini doğrudan tüketicilere sattı̆ğ [3] işletmeden tüketiciye e-ticaret türüdür [4]. Bu yeni alışveriş türüne elektronik alışveriş, çevrimiçi alışveriş, internet alışverişi, web tabanlı alışveriş gibi farklı adlar verilmektedir [5].

E-ticaret sektöründe mobil cihaz kullanımının yaygınlaşmasıyla, müşteriler birden fazla cihaz (kanal) arasında geçişler yaparak çevrimiçi alışverişi tamamlamaktadırlar. Örneğin, fiziksel mağazada ürüne dokunarak incelemesini yapan tüketici akıllı telefonunu kullanarak çevrimiçi alışverişi tamamlamaktadır. Dolayısıyla ürün riskini azaltan, ihtiyaç duyduğu ürünü daha ucuza satın alan tüketiciler müşteri değerini fazlalaştırabilmek gayesiyle bu şekilde davranmaktadırlar.

Deloitte tarafindan 2012 y1lından itibaren her y1 yapılan Global Mobil Kullanıcı anketinin 2017 yılı sonuçlarına göre, Türkiye'de kullanıcıların aktivitelerinin cihazlara göre dağılımına bakıldığında, cep telefonunun birçok aktivitede öncelikli olarak tercih edildiği gözlemlenmektedir. Genellikle 18-34 yaş grubu, $35-50$ yaş grubu ile kıyaslandığında cep telefonunun bilgisayara (dizüstü ve masaüstü) göre daha fazla tercih edildiği görülmektedir. $\mathrm{Bu}$ yaş grubunun özellikle alısveriș sitelerine göz atma ve internetten ürün satın alma aktivitelerinde cep telefonunu, dizüstü ve masaüstü bilgisayardan daha fazla kullanması dikkat çekmektedir. Diğer bir deyişle, tüketiciler alışverişe cep telefonunda başlayıp bilgisayarda bitirmektedirler [6]

Çevrimiçi alışveriş ile ilgili yazın, genel olarak çevrimiçi alışveriş veya perakende web siteleri üzerinden yapılan çevrimiçi alışveriş davranışı konuları çerçevesinde sınırlı kalmıştır. Tüketiciler tarafından çevrimiçi alışveriş sırasında kullanılan cihazlara odaklanan çalışmalar çok fazla bulunmamaktadır.

İnternet tabanlı televizyon ile yapılan çevrimiçi alışverişin konu edildiği çalışmada [7] hazcı (hedonic) güdülerin internet tabanlı televizyon üzerinden çevrimiçi alışverişe olan tutumun en güçlü belirleyicisi olduğu ortaya konulmuştur.

Finlandiya'da yapılan bir çalışmaya göre, 55-74 yaş grubundaki tüketiciler çevrimiçi alışveriş için mobil cihazı (akıllı telefon veya tablet) 55 yaş altı grubundaki tüketicilerle yaklaşık olarak aynı sıklıkta kullanmaktadırlar. Genç gruptaki erkeklerin mobil cihazla çevrimiçi alışverişe olan ilgisi, yaşlı gruptaki erkeklere göre daha fazladır [8].

$\mathrm{Bu}$ bağlamda, müşterilerin çevrimiçi alışveriş sürecini tamamlayıncaya kadar birden fazla cihazı (kanal) tercih etmelerine neden olan değişkenlerin belirlenmesi ve değişkenler arasındaki etkileşimlerin tüketicinin web tabanlı satın alma kararı üzerindeki etkisinin incelenmesi, çalışmanın temel amacını oluşturmaktadır.

\section{LITERATÜR ÖZETİ (SUMMARY OF LITERATURE)}

Dijital çağ olarak adlandırılan günümüz dünyasında insanlar gerek özel yaşamlarında gerekse iş yaşamlarında bilgiye kolay bir şekilde yer ve zaman gözetmeksizin ulaşabilmektedirler. İnternetle özdeşleșen dijital cihazları (ak1llı telefon, tablet, bilgisayar vb.) kendi yetenekleriyle örtüşen şekilde kullanabilen tüketiciler, hiçbir karşıllk beklemeden aradıkları bilginin peşinden giderek aldıkları kararlarla hedeflerini gerçekleştirip (çevrimiçi alışveriş) mutlu olmakta ve hayatların daha kaliteli hale getirmektedirler. Kullandıkları cihaz ve dijital ortam ile adeta bir bütün haline gelen tüketiciler bulundukları gerçek çevreden soyutlanmakta ve zamanın nasıl geçtiğini anlamayarak kendilerini yağmur suyunda sürüklenen bir yaprak misali akışa bırakmaktadırlar. Bu akış halinin kesintiye uğramaması noktasında söz konusu dijital cihazların teknik yeterlilik vb. unsurlarını kapsayacak şekilde kanal (sistem) kalitesi ve bilgi kalitesinin de irdelenmesi oldukça önem arz etmektedir. İçsel bir güdülenme olan akış deneyimi sonucunda tüketiciler içinde bulundukları etkinlikten memnuniyet duyabilmekte ve etkinliği tekrar deneme niyetinde olabilmektedirler.

Güdü (motivasyon) istekleri, arzuları, gereksinimleri, dürtüleri ve ilgileri kapsayan genel bir kavramdır. Açlık, susuzluk, cinsellik gibi fizyolojik kökenli güdülere dürtü (drive) adı verilir. İnsanlara özgü başarma isteği gibi yüksek dürtülere de gereksinme (ihtiyaç) denir. Güdüler organizmayı uyararak faaliyete geçirdikten sonra gerçekleșen davranışı belli bir amaca yöneltir. Bu iki 
özelliğin gözlemlenmesi organizmanın güdülenmiş olduğunu göstermektedir. Diğer bir deyişle, her davranışın altında bir güdü veya güdüler zinciri bulunmaktadır [9].

Güdülenme konusundaki başka bir önemli unsur ödüllerdir. Ödüller, iç ve dış kaynaklı olmak üzere ikiye ayrılırlar. İç kaynaklı ödül (intrinsic reward), yapılan davranışın içeriğinde saklı bulunan zevk ve doyum duygusuna verilen addır; faaliyetin kendisi, hangi nedenle olursa olsun, birey için doyum sağlamaktadır. Dış kaynaklı ödül (extrinsic reward) ise, davranışın içinde bulunmayan fakat davranışın yapılması için dışarıdan verilen ödül türüdür [9].

Optimum deneyim veya ototelik (autotelic) deneyim olarak da bilinen akış deneyiminin kökeni 1960'larda Maslow'un doruk deneyim çalışmalarına dayanan, 1970’lerde Csikszentmihalyi tarafından geliştirilen ve pozitif psikoloji içinde yer alan bir araştırma alanıdır [10].

Akış teorisinin temeli, çevresel etkenlerden (ödül, saygınlık vb.) bağımsız olarak kişinin içsel güdülenmesi ile bir eylemi gerçekleştirmesini anlayabilme eğilimine dayanmaktadir [11].

Akış deneyimi kendine has dinamik bir zihinsel durum olup öz gayeli deneyimi yaşayan insanların hissettikleri bütünsel bir duygudur. Öz gayeli (amacı kendisi olan) deneyim, kişinin benliğini tamamıyla içinde bulunduğu etkinliğe vermesiyle yaşanmaktadır [12].

Akış deneyiminin üç koşulu (öncülü) bulunmaktadır. Bu koşullar; etkinlikteki zorluklar ve kişinin yetenekleri (kapasite), etkinliğe ait net şekilde belirtilen hedefler ve etkinlikteki gelişmeleri gösteren hılı geribildirim mekanizmasıdır. Akış deneyimi, etkinlikteki zorlukların kişinin yetenekleriyle örtüşmesi sonucunda oluşan bir dengenin kurulmasıyla gerçekleşmektedir. Bu denge son derece kırılgandır. Kişi aldığı geribildirimlere göre yetenek veya zorluk seviyelerini gözden geçirerek yeniden akış deneyimini yaşamaya çalışmaktadır [13].

Trevino ve Webster (1992) akışı bilgi teknolojileri kapsamında dört boyutta ele almışlardır [14]:

- Kontrol boyutu: Kişinin teknoloji ile etkileşiminde deneyimlediği ortam üzerindeki kontrol duygusu.

- Dikkat odağı: Kişinin dikkatinin teknoloji ile ilgili olan bir uyarıcıya odaklanması.

- Merak: Akış deneyimi sırasında kişinin merak seviyesinin artması ve bir haz durumunun ortaya çıkması.
- İçsel ilgi: Kişinin teknolojiye ilgisinin ve onunla etkileşiminin yaşadığı haz duygusunu arttırması.

Kim ve Ko (2019) yaptıkları çalışmada, spor medyasındaki sanal gerçeklik oyunlarında kullanıcıların yaşadıkları akış deneyimlerinin memnuniyet üzerindeki etkisini incelemişlerdir [15].

Fidanboy (2019) çalışmasında, bilişim sektöründe görev yapan çalışanların yaşam doyumuna yönelik algıları, örgütsel özdeşleşme düzeyleri ve akış deneyimine yatkınlıkları arasındaki ilişkileri belirlemeye çalışmıştır [16].

Sanjamsai ve Phukao (2018) üniversite öğrencilerine uyguladıkları anket ile yaptıkları çalışmalarında, bilgisayar oyunu oynarken öğrencilerin deneyimledikleri akış halini oluşturan faktörleri incelemişlerdir. Araştırma sonuçlarında, seçilecek bilgisayar oyunlarının duygusal (emotional) akış deneyiminden daha fazla bilişsel (cognitive) akış deneyimini yaşatacak nitelikte olmaları gerektiğini ortaya koymuşlardır [17].

Akçakanat vd. (2019) tarafindan yapılan çalışmaya göre, Meslek Aşkının boyutlarının hem Akış Deneyimi boyutları ile hem de İş Tatmini ile pozitif yönlü anlamlı bir ilişki içerisindedir. Akış Deneyimi boyutlarının İş Tatmini ile olan ilişkisi de pozitif yönlü ve anlamlıdır. Meslek Aşkı boyutlarının İş Tatmini üzerine olan etkisinde Akış Deneyimi boyutlarının tümünün aracılık rolü bulunmaktadır [18].

Avcılar ve Yenilmez'e göre (2019) dağıtım kanallarının çeşitlenmesiyle beraber, birden fazla dağıtım kanalını aynı anda kullanmak isteyen perakendecilerin çok kanallı perakendecilik stratejilerine yönelmesi ve deneyimsel perakendecilik uygulamalarıyla, müşterilerin akış deneyimi yaşamalarını sağlaması, müşteri satın alma niyetinin ve memnuniyetinin sağlanmasında önem taşımaktadır [19].

Teknoloji Kabul Modelinde yer alan değişkenlerden algılanan fayda; bilgi teknolojisini kullanan kişinin iş performansındaki iyileşmeye olan inancını ifade etmektedir. Kullanıcı bilgi sistemlerinin kullanımı ile iş performansı arasındaki pozitif ilişkinin varlığına inanmaktadır. Algılanan kullanım kolaylığı ise; kişinin fazla bir çaba göstermeden bilgi sistemini kullanabileceğine olan inancının seviyesini ifade etmektedir [20].

Wu vd.'ne (2016) göre, çevrimiçi alışveriş sitesindeki algılanan fayda akış deneyiminin öncülüdür. Akış deneyimi anlık (plansız) çevrimiçi alışveriş niyetini olumlu etkilemektedir [21]. 
Teknoloji Kabul Modeline dayandırılarak çevrimiçi oyun oynama tutumunu ve davranışını etkileyen değişkenlerin irdelendiği çalışmaya göre, algılanan kullanım kolaylığ akış deneyiminin öncülü olup aralarında pozitif yönde bir ilişki bulunmaktadır [22]

Yeke vd. çalışmalarını (2019) İstanbul Üniversitesi İşletme Fakültesi'nde görev yapmakta olan kamu görevlilerinin elektronik belge otomasyon sistemini kullanmaya yönelik tutumlarını ortaya koyan faktörleri belirleyebilmek ve bu faktörler arasındaki ilişkileri tespit edebilmek amacıyla gerçekleştirmişlerdir. $\mathrm{Bu}$ doğrultuda anket yoluyla 53 kamu görevlisinden veri toplanmıştır. Yapılan analizlerin sonucunda algılanan fayda, algılanan kullanım kolaylığı, alışkanlık ve uyumluluk değişkenleri ile çalışanların elektronik belge otomasyon sistemini kullanmaya yönelik tutumları arasında anlamlı ilişkilerin var olduğu tespit edilmiştir [23].

Yıldırır ve Kaplan (2019) çalışmalarında mobil uygulamalara yönelik algılanan faydayı ve algılanan kullanım kolaylığını incelemek ve mobil uygulama kullanımına yönelik tutum, niyet ve gerçekleşen kullanım arasındaki ilişkileri tespit etmeyi amaçlamışlardır. Çalışma sonucunda, kolay kullanıma sahip uygulamaların kullanıcıların seçiminde büyük bir etki yarattığ 1 anlaşılmıştır. Kullanıcılar çoğunlukla kolay anlaşılır, hantal olmayan ve kolaylıkla fayda sağlayabilecekleri uygulamaları seçmektedirler [24].

Kalyoncuoğlu (2018) çalışmasında tüketicilerin online alışverişlerinde ödeme işlemlerinin güvenilirliği için Sanal Kart kullanımlarının kabulünü etkileyen faktörleri Teknoloji Kabul Modeli ile incelemiştir. Online alışverişlerinde Sanal Kart kullanan 490 tüketiciye ulaşılan çalışmada, Sanal Kart kullanımının kabulünü açıklamada Yapısal Eşitlik Modeli (YEM) kullanılmıştır. Araştırma sonuçları, gerçekleşen davranış (online alışverişlerinde Sanal Kart kullanımı) açısından; tüketicinin algılanan fayda, algılanan kullanım kolaylığı, tutum ve davranışsal niyet düzeyinin önemli belirleyici etkileri olduğunu ortaya koymaktadır [25]

Yapılan araştırmalar çevrimiçi alışverişin akış deneyimini sağlayan bir etkinlik olduğunu belirtmektedir. Çünkü internette bilgiyi aramak tüketicilerin tecrübe ettiği bir zorluk (meydan okuma) olmakla birlikte bu zorluğun üstesinden gelebilmek ve başarılı bir alışveriş deneyimini gerçekleştirebilmek için tüketicilerin belirli bir seviyedeki bilgisayar kullanma yeteneğine (computer skill) sahip olması gerekmektedir [26].

Bilgi sistemi olarak e-ticaret uygulamalarının başarısında bilgi ve kanal kalitesi önemli rol oynamaktadır. Çalışmada bilgi kalitesi ve kanal kalitesi değişkenlerinin çevrimiçi alışveriş kanallarında yaşanan akış deneyiminin memnuniyet üzerindeki etkisini düzenleyebilecekleri öngörülmektedir. Bu iki kalite unsuru Bilgi Sistemleri Başarı Modeli içerisinde yer almaktadır. Çalışmada ve araştırma modelinde elektronik cihazlar dikkate alınarak sistem kalitesi değişkeni kanal kalitesi olarak adlandırılmıştır.

DeLone ve McLean (1992) tarafından geliştirilen Bilgi Sistemleri Başarı Modeli bilgi sistemleri yazınında sıkça kullanılan modellerden biri olmuştur. Modeli oluşturan değişkenlerden bilgi kalitesi ve sistem kalitesi şu şekilde açıklanmaktadır [27]:

- Bilgi kalitesi: Sistemin ürettiği bilgi ya da çıktı kalitesi ifade etmektedir. Bilgi kalitesini ölçme kriterleri arasında doğruluk, duyarlılık, güncellik, gerçeklilik, tamlık, özgülük, uygunluk, yeterlilik, anlaşılabilirlik gibi faktörler bulunmaktadır.

- Sistem kalitesi: Bilgi sisteminin sahip olduğu kendisine özgü bazı özellikler ile tanımlanmaktadır. Bu özellikler, erişim kolaylığı, sistemin entegrasyonu, beklentilerin karşılanması, sistemin yanıt süresi, güvenilirlik, kullanım kolaylığı, algılanan fayda, özelleştirme, verimlilik şeklinde sıralanmaktadır.

\section{MATERYAL VE METOT (MATERIAL AND METHOD)}

$\mathrm{Bu}$ bölümde araştırmanın amacı, araştırma modeli ve hipotezler, örneklem seçimi ve veri toplama yöntemi başlıkları yer almaktadır.

\subsection{Araștırmanın Amacı (Research Objective)}

Mobil ticaretin gelişimi ile birlikte birden fazla elektronik cihaz kullanarak çevrimiçi alışveriş sürecinin tamamlanması son dönemlerdeki araştırma raporlarında cihazlar arası işlem (cross device transaction) olarak ortaya konmaktadır. Bu bağlamda internet üzerinden alışverişin yapılabilmesi için farklı elektronik cihazların tercih edilmesine neden olan etkenlerin belirlenmesi araştırmanın temel amacını oluşturmaktadır.

\subsection{Araştırma Modeli ve Hipotezler (Research Model and Hypothesis)}

Araştırma modeli tüketicilerin çevrimiçi satın alma sürecinde kullandıkları elektronik cihazların (akıllı telefon, tablet, dizüstü bilgisayar, masaüstü bilgisayar) seçimini 
etkileyen değişkenleri ve bu değişkenler arasındaki etkileşimleri açıklayabilmek amacıyla ortaya konmuştur.

Modelde yer alan cihazların kullanımından algılanan fayda ve cihazların kullanım kolaylığı değişkenleri akış deneyiminin öncüllerini oluşturmaktadır. Akış deneyiminin cihazlardan duyulan memnuniyeti (elektronik cihazları kullanma deneyiminin müşteri beklentilerini karşılamas1) etkilediği ve bu etkinin üzerinde bilgi kalitesi ve kanal kalitesi değişkenlerinin düzenleyici rolünün olduğu öngörülmektedir. Memnuniyet değişkeninin çevrimiçi satın alma kararı değişkenini etkilediği varsayılmaktadır. Aynı zamanda ürün ilgilenim düzeyinin rolü de araştırmada incelenmiştir. Tüketicilerin ilgilenim düzeylerinin ölçüldüğü ürünlerden düşük ilgilenim düzeyindeki ürün olarak hediyelik eşya ve kırtasiye, yüksek ilgilenim düzeyindeki ürün olarak da teknoloji ürünleri seçilmiştir.

Model değişkenlerine ilişkin ölçekler; algılanan fayda ve algılanan kullanım kolaylığı ölçekleri [28]; bilgi kalitesi ölçeği [29]; kanal kalitesi ölçeği, [30]; akış deneyimi [31]; memnuniyet [32] ve çevrimiçi satın alma kararı ölçeğinden [33] oluşmaktadır.

Araştırmaya ait geliştirilen altı ana hipotez şu şekilde siralanmaktadir:

H1: Cihazların kullanımından algılanan faydanın cihazlar ile edinilen akış deneyimi üzerinde olumlu bir etkisi vardir.

H2: Cihazların kullanım kolaylığının cihazlar ile edinilen akış deneyimi üzerinde olumlu bir etkisi vardır.

H3: Cihazlar ile edinilen akış deneyiminin cihazların kullanımından duyulan memnuniyet üzerinde olumlu bir etkisi vardır.

H4: Bilgi kalitesi, cihazlar ile edinilen akış deneyiminin cihazların kullanımından duyulan memnuniyet üzerindeki etkisini düzenleyicidir.

H5: Kanal kalitesi, cihazlar ile edinilen akış deneyiminin cihazların kullanımından duyulan memnuniyet üzerindeki etkisini düzenleyicidir.

H6: Cihazların kullanımından duyulan memnuniyetin çevrimiçi satın alma kararı üzerinde olumlu bir etkisi vardir.

\subsection{Anakütle ve Örneklem Seçimi (Choosing Population and} Sample)

Araştırmanın anakütlesini mobil cihaz (akıllı telefon, tablet) ya da bilgisayar (dizüstü bilgisayar, masaüstü bilgisayar) kullanarak çevrimiçi satın alma yapan ve İstanbul'da ikamet eden 18 yaş ve üzerindeki tüketiciler oluşturmaktadır. Tesadüfi olmayan örnekleme yöntemlerinden kolayda örnekleme kullanılmış [34] olup bu nedenle örneklemin büyüklüğü aşağıdaki şekilde hesaplanmış olmakla beraber geniş tutulmuştur.

\section{p: Akış deneyiminden memnun olanların oranı}

$q: 1-p$

\section{Z: \%95 güvenlik düzeyinde normal değer $( \pm 1,96)$}

$$
\begin{aligned}
& E: \text { Tolerans }( \pm \% 3) \\
& n=p * q *(Z / e)^{2} \\
& n=0,5 * 0,5 *(1,96 / 0,03)^{2} \\
& n=1067 \mathrm{kişi}
\end{aligned}
$$

\subsection{Veri Toplama Yöntemi ve Aracı (Data Collection Method)}

Tanımlayıcı araştırma yöntemi benimsenerek modelde bulunan değişkenlerle ilgili doğru tanımların yapılması hedeflenmiştir [34]. Bu hedefe yönelik birincil verilerin toplanması için anket yöntemi uygulanmıştır [34]. Anket formunda yaş, cinsiyet, öğrenim düzeyi soruları dışında değerlenmesi gereken 19 tane yargı bulunmaktadır. Beş noktalı Likert ölçeği kullanılmıştır.

\section{VERİ ANALIZİ VE BULGULAR (FINDINGS)}

$\mathrm{Bu}$ bölümde tanımlayıcı bilgiler, güvenilirlik analizi sonuçları ve hipotez testleri başlıkları yer almaktadır.

\subsection{Tanımlayıcı Bilgiler (Descriptive Data)}

Cevaplayıcıların \%50'sinden fazlası 18-30 yaş grubunda bulunmaktadır. Cevaplayıcıların \%50'sinden fazlasını kadınlar oluşturmaktadır. Cevaplayıcılar eğitim düzeylerine göre değerlendiğinde \%95,5'inin önlisans, lisans ve üstü eğitim düzeyine sahip oldukları görülmektedir.

\subsection{Güvenilirlik Analizi Sonuçları (Reliability Test Results)}

Araştırma modelinde yer alan değişkenlere ilişkin güvenilirlik analizleri Cronbach alpha $(\alpha)$ ile yapılmış olup güvenilirlik katsayısı düşük çıkan değişkenler ayrıca açımlayıcı faktör analizine tabi tutulmuş; ancak faktör yükleri arasında önemli bir farklılık olmadığı görülmüştür. Ölçekler bu şekliyle analize alınmıştır. Analiz sonuçları Tablo 1'de gösterilmiştir. 
Tablo 1. Güvenilirlik Analizi Sonuçları (Reliability Test Results)

\begin{tabular}{|l|c|c|c|c|c|}
\hline & \multirow{2}{*}{$\begin{array}{c}\text { Tüm } \\
\text { Kulla } \\
\text { neğişkenler }\end{array}$} & \multicolumn{2}{|c|}{$\begin{array}{c}\text { Ürün ilgilenim düzeyi } \\
\text { nüsük } \\
\text { (Kate } \\
\text { gorisi } \\
\text { z) }\end{array}$} & $\begin{array}{c}\text { Ürün ilgilenim düzeyi } \\
\text { yüksek }\end{array}$ & \multicolumn{2}{|c|}{$\begin{array}{c}\text { Mobil } \\
\text { Cihaz }\end{array}$} & Bilgisayar & $\begin{array}{c}\text { Mobil } \\
\text { Cihaz }\end{array}$ & Bilgisayar \\
\hline $\begin{array}{l}\text { Algılanan } \\
\text { Fayda } \\
\text { (3 soru) }\end{array}$ & 0,903 & 0,899 & 0,920 & 0,909 & 0,916 \\
\hline $\begin{array}{l}\text { Algılanan } \\
\text { Kullanım } \\
\text { Kolaylığ } \\
\text { (3 soru) }\end{array}$ & 0,940 & 0,909 & 0,922 & 0,897 & 0,922 \\
\hline $\begin{array}{l}\text { Ak1ş } \\
\text { Deneyimi } \\
\text { (3 soru) }\end{array}$ & 0,870 & 0,629 & 0,634 & 0,624 & 0,659 \\
\hline $\begin{array}{l}\text { Bilgi } \\
\text { Kalitesi } \\
\text { (3 soru) }\end{array}$ & 0,917 & 0,863 & 0,888 & 0,851 & 0,882 \\
\hline $\begin{array}{l}\text { Kanal } \\
\text { Kalitesi } \\
\text { (2 soru) }\end{array}$ & 0,847 & 0,574 & 0,703 & 0,584 & 0,684 \\
\hline $\begin{array}{l}\text { Memnuniyet } \\
\text { (3 soru) }\end{array}$ & 0,899 & 0,791 & 0,788 & 0,804 & 0,805 \\
\hline $\begin{array}{l}\text { Çevrimiçi } \\
\text { Satın alma } \\
\text { Kararı } \\
\text { (2 soru) }\end{array}$ & 0,906 & 0,854 & 0,874 & 0,856 & 0,878 \\
\hline
\end{tabular}

\subsection{Hipotez Testleri (Hypotesis Tests)}

Normallik varsayımı, betimsel, grafiksel ve istatistiksel olmak üzere farklı yöntemlerle irdelenebilmektedir [35, 36].

Betimsel yöntemler arasında verilere ait aritmetik ortalama, mod, medyan, çarpıklık ve basıklık katsayıları gibi istatistiklerin incelenmesi yer almaktadır. Aritmetik ortalama, mod ve medyanın eşit ya da yakın olması, çarpıklık ve basıklık katsayılarının \pm 1 sınırları içinde olması, standart sapma ile ortalamanın oranını yüzde olarak ifade eden bağıl değişim katsayısının 20 ile 25 aralığında olması normal dağılımın varlığına kanıt olarak gösterilmektedir [36].

Basit Doğrusal Regresyon Analizi yapılmadan önce normallik varsayımı koşullarının varlığ bağlamda, değişkenlerin ortalama, mod ve medyan değerlerinin birbirine yakın olduğu, çarpıklık ve basıklık katsayılarının +1 ile -1 arasında bulunduğu ve bağıl değişim katsayısının \%25'ten küçük olduğu görülmüştür.

Normallik varsayımının incelenmesine ait değerler Tablo 2'de belirtilmiştir.

Pearson korelasyon analizi normal dağılım göstermekte olan çalışma verilerine uygulanmıştır.

Tablo 3'te korelasyon katsayıları ve önem dereceleri belirtilmiştir.
Değişkenler arasında pozitif doğrusal bir ilişki $(\mathrm{p}<0,01)$ olduğu görülmektedir. Bilgisayarla yüksek ilgilenim düzeyli ürün alışverişine ait memnuniyet ile satın alma değişkenleri $(R=0,734)$ arasındaki ilişki düzeyi en güçlü olanıdır.

Tablo 2. Normallik Testi Sonuçları (Normality Test Results)

\begin{tabular}{|c|c|c|c|c|}
\hline \multirow{2}{*}{ Değişkenler } & \multicolumn{2}{|c|}{$\begin{array}{l}\text { Ürün ilgilenim düzeyi } \\
\text { düşük }\end{array}$} & \multicolumn{2}{|c|}{$\begin{array}{l}\text { Ürün ilgilenim düzeyi } \\
\text { yüksek }\end{array}$} \\
\hline & $\begin{array}{l}\text { Mobil } \\
\text { Cihaz }\end{array}$ & Bilgisayar & $\begin{array}{l}\text { Mobil } \\
\text { Cihaz }\end{array}$ & Bilgisayar \\
\hline \multirow{3}{*}{$\begin{array}{l}\text { Algilanan } \\
\text { Fayda }\end{array}$} & Ç: $-0,95$ & Ç: 0,75 & Ç: $-0,90$ & 0,85 \\
\hline & B: 0,31 & B: $-0,82$ & B: $-0,02$ & B: $-0,66$ \\
\hline & $\mathrm{K}: \quad 0,26$ & $\mathrm{~K}: \quad 0,22$ & $\mathrm{~K}: 0,27$ & $\mathrm{~K}: \quad 0,22$ \\
\hline \multirow{3}{*}{$\begin{array}{l}\text { Algilanan } \\
\text { Kullanım } \\
\text { Kolaylığı }\end{array}$} & Ç: $-0,42$ & Ç: $-0,34$ & Ç: $-0,35$ & Ç: $-0,37$ \\
\hline & B: $\quad 0,97$ & B: 0,68 & B: 0,79 & B: $\quad 0,93$ \\
\hline & $\mathrm{K}: \quad 0,21$ & $\mathrm{~K}: \quad 0,21$ & $K: 0,20$ & $\mathrm{~K}: \quad 0,20$ \\
\hline \multirow{3}{*}{$\begin{array}{l}\text { Akış } \\
\text { Deneyimi }\end{array}$} & Ç: $-0,46$ & Ç: $-0,44$ & Ç: $-0,43$ & Ç: $-0,48$ \\
\hline & B: 0,10 & B: 0,10 & B: 0,07 & B: 0,19 \\
\hline & $\mathrm{K}: \quad 0,25$ & $\mathrm{~K}: 0,22$ & $K: 0,25$ & $\mathrm{~K}: \quad 0,23$ \\
\hline \multirow{3}{*}{$\begin{array}{l}\text { Bilgi } \\
\text { Kalitesi }\end{array}$} & Ç: $-0,66$ & Ç: $-0,82$ & Ç: $-0,78$ & Ç: $-0,91$ \\
\hline & B: 0,09 & B: 0,43 & B: 0,38 & B: 0.75 \\
\hline & $\mathrm{K}: 0,26$ & $\mathrm{~K}: 0,24$ & $\mathrm{~K}: 0,24$ & $\mathrm{~K}: \quad 0,22$ \\
\hline \multirow{3}{*}{$\begin{array}{l}\text { Kanal } \\
\text { Kalitesi }\end{array}$} & Ç: $-0,51$ & Ç: $-0,93$ & Ç: $-0,49$ & Ç: $-0,92$ \\
\hline & B: 0,39 & B: 0,16 & B: 0,31 & B: $\quad 0,17$ \\
\hline & $\mathrm{K}: 0,24$ & $\mathrm{~K}: 0,21$ & $\mathrm{~K}: 0,24$ & $\mathrm{~K}: \quad 0,21$ \\
\hline \multirow[t]{3}{*}{ Memnuniyet } & Ç: $-0,82$ & Ç: $-0,90$ & Ç: $-0,74$ & Ç: $-0,87$ \\
\hline & B: 0,62 & B: 0,86 & B: 0,34 & B: 0,62 \\
\hline & $\mathrm{K}: 0,24$ & $\mathrm{~K}: 0,21$ & $\mathrm{~K}: 0,24$ & $\mathrm{~K}: 0,23$ \\
\hline \multirow{3}{*}{$\begin{array}{l}\text { Çevrimiçi } \\
\text { Satın alma } \\
\text { Kararı }\end{array}$} & Ç: 0,07 & Ç: $-0,26$ & Ç: 0,11 & Ç: $-0,23$ \\
\hline & B: $-0,85$ & B: $-0,87$ & B: $-0,91$ & B: $-0,97$ \\
\hline & $\mathrm{K}: 0,21$ & $\mathrm{~K}: 0,23$ & $\mathrm{~K}: 0,25$ & $K: 0,22$ \\
\hline
\end{tabular}

Şekil 1, şekil 2 ve şekil 3'te gösterilen düzeltilmiş hata regresyon grafikleri incelendiğinde, dağılımlarda önemli sapmaların olmadığı görülmektedir. Aynı dağılımların diğer cihaz ve ilgilenim düzeyi gruplarında da gerçekleştiği belirlenmiştir.

Basit Doğrusal Regresyon Analizi sonucunda etki düzeylerini gösteren regresyon katsayıları Tablo 4 ve Tablo 5'te gösterilmektedir. Regresyon katsayılarının mobil cihazlar ve bilgisayarlara göre hem düşük hem de 
yüksek mal ilgilenim düzeyleri bağlamında değerlenmesi sonucunda tüm hipotezlerin kabul edildiği görülmektedir.

Örneğin, tablo 4'te bulunan algılanan faydanın akış deneyimine etkisi incelendiğinde, R-kare $=0,200$ değeri, mobil cihaz ile ilgilenim düzeyi yüksek ürün için çevrimiçi alışveriş yapanlarda algılanan faydanın akış deneyimi üzerinde \%20 etkisi olduğunu ifade etmektedir. $B=0,382$ katsayısı da algılanan faydada yaşanacak 1 birimlik değişimin akış deneyiminde 0,382 birim değişime neden olacağını açıklamaktadır.

Tablo 3. Korelasyon Katsayıları (Correlation Coefficients)

\begin{tabular}{|c|c|c|c|}
\hline & $\begin{array}{l}\text { Mal İlgilenim } \\
\text { Düzeyi }\end{array}$ & $\mathrm{R}$ & $\mathrm{P}$ \\
\hline \multirow{6}{*}{$\begin{array}{l}\text { Algılanan fayda } \\
\text { ile akış } \\
\text { deneyimi } \\
\text { ilişkisi }\end{array}$} & $\begin{array}{l}\text { İlgilenim Düzeyi } \\
\text { Düşük }\end{array}$ & & \\
\hline & Mobil cihaz & 0,448 & 0,000 \\
\hline & Bilgisayar & 0,477 & 0,000 \\
\hline & $\begin{array}{l}\text { İlgilenim Düzeyi } \\
\text { Yüksek }\end{array}$ & & \\
\hline & Mobil cihaz & 0,419 & 0,000 \\
\hline & Bilgisayar & 0,470 & 0,000 \\
\hline \multirow{6}{*}{$\begin{array}{l}\text { Algılanan } \\
\text { kullanım } \\
\text { kolaylığı ile } \\
\text { akış deneyimi } \\
\text { ilişkisi }\end{array}$} & $\begin{array}{l}\text { İlgilenim Düzeyi } \\
\text { Düşük }\end{array}$ & & \\
\hline & Mobil cihaz & 0,363 & 0,000 \\
\hline & Bilgisayar & 0,406 & 0,000 \\
\hline & $\begin{array}{l}\text { İlgilenim Düzeyi } \\
\text { Yüksek }\end{array}$ & & \\
\hline & Mobil cihaz & 0,371 & 0,000 \\
\hline & Bilgisayar & 0,417 & 0,000 \\
\hline \multirow{6}{*}{$\begin{array}{l}\text { Akış deneyimi } \\
\text { ile memnuniyet } \\
\text { ilişkisi }\end{array}$} & $\begin{array}{l}\text { İlgilenim Düzeyi } \\
\text { Düşük }\end{array}$ & & \\
\hline & Mobil cihaz & 0,635 & 0,000 \\
\hline & Bilgisayar & 0,656 & 0,000 \\
\hline & $\begin{array}{l}\text { İlgilenim Düzeyi } \\
\text { Yüksek }\end{array}$ & & \\
\hline & Mobil cihaz & 0,616 & 0,000 \\
\hline & Bilgisayar & 0,645 & 0,000 \\
\hline \multirow{6}{*}{$\begin{array}{l}\text { Memnuniyet ile } \\
\text { satın alma } \\
\text { kararı ilişkisi }\end{array}$} & $\begin{array}{l}\text { İlgilenim Düzeyi } \\
\text { Düşük }\end{array}$ & & \\
\hline & Mobil cihaz & 0,667 & 0,000 \\
\hline & Bilgisayar & 0,733 & 0,000 \\
\hline & $\begin{array}{c}\text { İlgilenim Düzeyi } \\
\text { Yüksek }\end{array}$ & & \\
\hline & Mobil cihaz & 0,682 & 0,000 \\
\hline & Bilgisayar & 0,734 & 0,000 \\
\hline
\end{tabular}

Düzenleyici değişken, bağımsız değişken ile bağıml değişken arasındaki ilişkinin yönünü ve gücünü değiştirebilen değişken olarak bilinmektedir [37]. Bu bağlamda bağımsız değişken ile düzenleyici rolü araştırılan değişkenin çarpımıyla elde edilen etkileşim terimi, regresyon modeline dahil edildiğinde bağıml değişken üzerinde anlamlı bir etkiye sahip ise düzenleyici değişkenin ve düzenleyici etkinin varlığı kabul edilmektedir [38]. Çalışmada bilgi kalitesi ve kanal kalitesi değişkenlerinin düzenleyici etkisinin ölçülebilmesi amacıyla oluşturulan 1. etkileşim terimi: Akış Deneyimi x Bilgi Kalitesi ve 2. etkileşim terimi: Akış Deneyimi $\mathrm{x}$ Kanal Kalitesi seklinde Tablo 5'te yer almaktadır. Söz konusu etkileşim terimleri ayrı ayrı Basit Doğrusal Regresyon Analizine dahil edilmişlerdir.

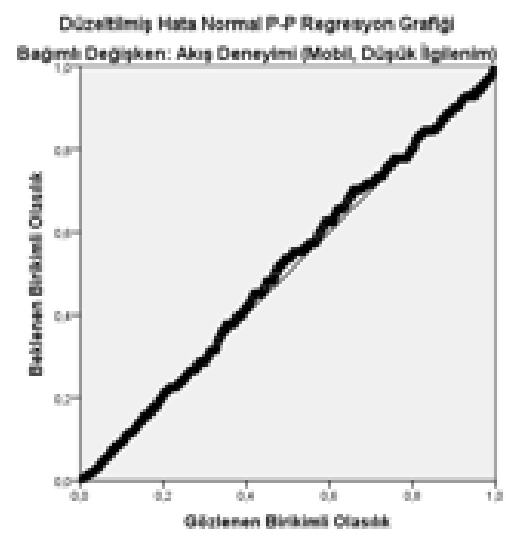

Şekil 1. Düzeltilmiş Hata Normal P-P Regresyon Grafiği (Akış Deneyimi)

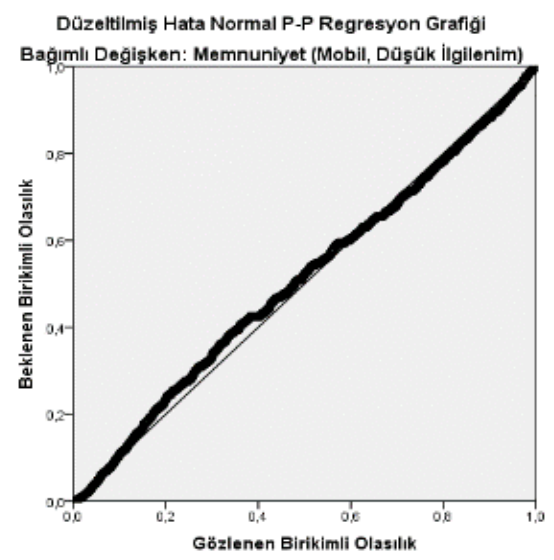

Şekil 2. Düzeltilmiş Hata Normal P-P Regresyon Grafiğgi (Memnuniyet)

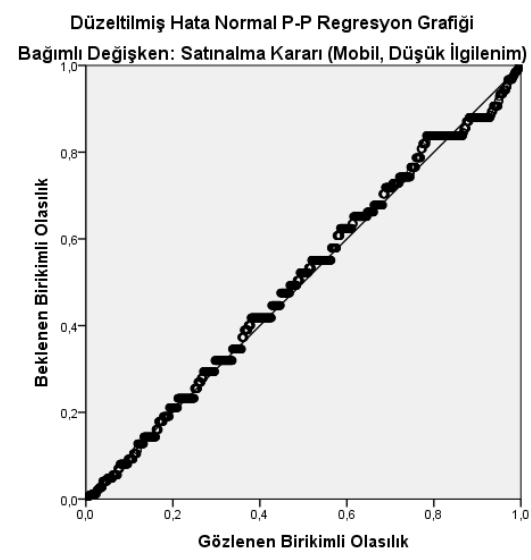

Şekil 3. Düzeltilmiş Hata Normal P-P Regresyon Grafiği (Satınalma Kararı) 
Tablo 4. Regresyon Modellerinde Etkiyi Gösteren Regresyon Katsayılar (Regression Coefficients in the Model)

\begin{tabular}{|c|c|c|c|c|c|c|}
\hline & $\begin{array}{l}\text { Mal İlgilenim } \\
\text { Düzeyi }\end{array}$ & $\mathrm{R}^{2}$ & $\mathrm{~F}$ & $P$ & B & $\begin{array}{c}\text { Hipotez } \\
\text { Kararı }\end{array}$ \\
\hline \multirow{6}{*}{$\begin{array}{l}\text { Algılanan } \\
\text { faydanın akış } \\
\text { deneyimine } \\
\text { etkisi }\end{array}$} & $\begin{array}{l}\text { İlgilenim Düzeyi } \\
\text { Düşük }\end{array}$ & & & & & \\
\hline & Mobil cihaz & 0,200 & 352,522 & 0,000 & 0,382 & Kabul \\
\hline & Bilgisayar & 0,227 & 413,142 & 0,000 & 0,429 & Kabul \\
\hline & $\begin{array}{c}\text { İlgilenim Düzeyi } \\
\text { Yüksek }\end{array}$ & & & & & \\
\hline & Mobil cihaz & 0,176 & 300,261 & 0,000 & 0,342 & Kabul \\
\hline & Bilgisayar & 0,220 & 397,580 & 0,000 & 0,429 & Kabul \\
\hline \multirow{6}{*}{$\begin{array}{l}\text { Algılanan } \\
\text { kullanım } \\
\text { kolaylığının } \\
\text { akış deneyimine } \\
\text { etkisi }\end{array}$} & $\begin{array}{l}\text { İlgilenim Düzeyi } \\
\text { Düşük }\end{array}$ & & & & & \\
\hline & Mobil cihaz & 0,132 & 214,051 & 0,000 & 0,348 & Kabul \\
\hline & Bilgisayar & 0,165 & 276,829 & 0,000 & 0,386 & Kabul \\
\hline & $\begin{array}{l}\text { İlgilenim Düzeyi } \\
\text { Yüksek }\end{array}$ & & & & & \\
\hline & Mobil cihaz & 0,137 & 223,798 & 0,000 & 0,363 & Kabul \\
\hline & Bilgisayar & 0,174 & 295,311 & 0,000 & 0,403 & Kabul \\
\hline \multirow{6}{*}{$\begin{array}{l}\text { Akış } \\
\text { deneyiminin } \\
\text { memnuniyete } \\
\text { etkisi }\end{array}$} & $\begin{array}{l}\text { İlgilenim Düzeyi } \\
\text { Düşük }\end{array}$ & & & & & \\
\hline & Mobil cihaz & 0,403 & 950,231 & 0,000 & 0,663 & Kabul \\
\hline & Bilgisayar & 0,431 & 1064,492 & 0,000 & 0,669 & Kabul \\
\hline & $\begin{array}{c}\text { İlgilenim Düzeyi } \\
\text { Yüksek }\end{array}$ & & & & & \\
\hline & Mobil cihaz & 0,379 & 859,543 & 0,000 & 0,659 & Kabul \\
\hline & Bilgisayar & 0,415 & 999,460 & 0,000 & 0,688 & Kabul \\
\hline
\end{tabular}

Tablo 5. Regresyon Modellerinde Etkiyi Gösteren Regresyon Katsayıları (Regression Coefficients in the Model)

\begin{tabular}{|c|c|c|c|c|c|c|}
\hline & $\begin{array}{l}\text { Mal İlgilenim } \\
\text { Düzeyi }\end{array}$ & $\mathrm{R}^{2}$ & $\mathrm{~F}$ & $\mathrm{P}$ & B & $\begin{array}{c}\text { Hipotez } \\
\text { Kararı }\end{array}$ \\
\hline \multirow{6}{*}{$\begin{array}{l}\text { Akış deneyiminin } \\
\text { memnuniyete } \\
\text { etkisinde bilgi } \\
\text { kalitesinin } \\
\text { düzenleyici rolü } \\
\text { (Akış Deneyimi x } \\
\text { Bilgi Kalitesi) }\end{array}$} & $\begin{array}{l}\text { İlgilenim Düzeyi } \\
\text { Düşük }\end{array}$ & & & & & \\
\hline & Mobil cihaz & 0,423 & 514,948 & 0,000 & 0,044 & Kabul \\
\hline & Bilgisayar & 0,481 & 650,550 & 0,000 & 0,067 & Kabul \\
\hline & $\begin{array}{c}\text { İlgilenim Düzeyi } \\
\text { Yüksek }\end{array}$ & & & & & \\
\hline & Mobil cihaz & 0,401 & 469,532 & 0,000 & 0,050 & Kabul \\
\hline & Bilgisayar & 0,467 & 616,085 & 0,000 & 0,074 & Kabul \\
\hline \multirow{6}{*}{$\begin{array}{l}\text { Akış deneyiminin } \\
\text { memnuniyete } \\
\text { etkisinde kanal } \\
\text { kalitesinin } \\
\text { düzenleyici rolü } \\
\text { (Akış Deneyimi x } \\
\text { Kanal Kalitesi) }\end{array}$} & $\begin{array}{l}\text { İlgilenim Düzeyi } \\
\text { Düşük }\end{array}$ & & & & & \\
\hline & Mobil cihaz & 0,424 & 516,311 & 0,000 & 0,052 & Kabul \\
\hline & Bilgisayar & 0,472 & 628,148 & 0,000 & 0,070 & Kabul \\
\hline & $\begin{array}{c}\text { İlgilenim Düzeyi } \\
\text { Yüksek }\end{array}$ & & & & & \\
\hline & Mobil cihaz & 0,400 & 468,217 & 0,000 & 0,053 & Kabul \\
\hline & Bilgisayar & 0,449 & 571,700 & 0,000 & 0,066 & Kabul \\
\hline \multirow{6}{*}{$\begin{array}{l}\text { Memnuniyetin } \\
\text { satın alma } \\
\text { kararına etkisi }\end{array}$} & $\begin{array}{c}\text { İlgilenim Düzeyi } \\
\text { Düsük }\end{array}$ & & & & & \\
\hline & Mobil cihaz & 0,445 & 1128,368 & 0,000 & 0,841 & Kabul \\
\hline & Bilgisayar & 0,538 & 1636,042 & 0,000 & 1,008 & Kabul \\
\hline & $\begin{array}{c}\text { İlgilenim Düzeyi } \\
\text { Yüksek }\end{array}$ & & & & & \\
\hline & Mobil cihaz & 0,465 & 1223,507 & 0,000 & 0,860 & Kabul \\
\hline & Bilgisayar & 0,539 & 1647,039 & 0,000 & 1,000 & Kabul \\
\hline
\end{tabular}

\section{SONUÇ VE ÖNERILER (RESULT AND DISCUSSIONS)}

Araştırmaya göre, hem mobil cihazlardaki hem de bilgisayarlardaki algılanan kullanım kolaylığı ve algılanan fayda akış deneyimini olumlu etkilemektedir.
Çevrimiçi alışveriş yaparken bilgisayar kullanmanın kolay ve faydalı olduğunu düşünen kullanıcılar mobil cihaz kullanıcılarına göre akış deneyimini daha fazla yaşamaktadırlar. Tüketicilerin bir bölümünün elektronik 
cihazlar ile çevrimiçi alışveriş yaparken alışverişe odaklandıkları, kontrolün kendilerinde olduğunu hissettikleri ve alışverişi eğlenceli buldukları yönünde verilere ulaşılmıştır.

Çalışmada, akış halini deneyimleyen kullanıcıların cihazlardan kaynaklı memnuniyet seviyelerinin yüksek olduğu görülmektedir. $\mathrm{Bu}$ durumda kullanıcılar web sitesinde daha fazla süre harcayacakları için çevrimiçi alışveriş sitelerindeki tasarım yaklaşımlarına daha fazla önem verilmesi gerekmektedir.

Araştırma verilerine göre, bilgi kalitesi ve kanal kalitesi, bilgisayar ve mobil cihazlardaki akış deneyiminin memnuniyet üzerindeki etkisinde düzenleyici bir rol oynamaktadır. Her iki mal ilgilenim düzeyinde de bilgisayarlardaki bilgi ve kanal kalitesinin düzenleyici rolü mobil cihazlara göre daha fazladır. Ekranların daha büyük olması ve yüksek işlem güçleri ile bilgisayarlar mobil cihazlara göre daha iyi bir kanal ve bilgi kalitesi sunmaktadirlar.

Araştırma cihazlardan duyulan memnuniyetin çevrimiçi satın alma kararı üzerindeki olumlu etkisini ortaya koymaktadır. Mobil cihazlar ile karşılaştırıldığında bilgisayarlardan duyulan memnuniyet çevrimiçi satın alma kararını hem iki mal ilgilenim düzeylerinde daha fazla etkilemiştir.

Cihazlarda sergilenen mallara ait bilgilerin sunumu iyi bir şekilde yapılmalıdır. İşletmeler web sayfalarında kişiselleştirme unsuruna odaklanmalı ve birden fazla kanalda (bilgisayar, akıllı telefon, tablet vb.) mallarını sergileyerek pazarlama faaliyetlerini yürütmelidirler.

Mobil cihazların kullanımı hızla yaygınlaştığı için işletmelerin ülkemizde gelişmekte olan mobil ticaret alanına çok daha fazla yoğunlaşarak mobil uygulamalara ve mobil teknolojiye olan yatırımlarını artırmaları gerekmektedir.

Araştırmanın farklı ülkelerde yapılarak aradaki değişimlerin ortaya çıkartılması akademik faydayı arttıracaktır. Düzenleyici rollerin farklı değişkenler ile incelenmesi, daha güçlü ölçeklerin kullanılması ve akış deneyiminin öncülü olarak farklı değişkenlerin eklenmesi bilimsel gelişime katkı sağlayacaktır.

\section{ARAŞTIRMA KISITLARI (RESEARCH CONSTRAINTS)}

Araştırmanın kısıtları, tesadüfi olmayan örnekleme yöntemlerinden kolayda örneklemenin kullanılması, akış deneyiminin memnuniyete etkisinde düzenleyici rolü oynayacak değişkenlerin seçimi, ölçeklerde soru sayısının daha fazla olması gerekliliği ve akış deneyimi değişkeninin öncüllerinin belirlenmesi şeklinde sıralanmaktadır.

\section{KAYNAKLAR (REFERENCES)}

[1] S. K. Mirze, İşletme. İstanbul: Literatür Yayıncılık, 2010

[2] D. Chaffey, E-business and e-commerce management: strategy, implementation, and practice, 4. bs., England: Pearson Education, 2009.

[3] R. Ganapathi, "A study on factors affecting online shopping behavior of consumers in Chennai", Journal of Management Research and Analysis, 2(2), 123-126, 2015.

[4] S. Y. Chen, R. D. Macredie, "The assessment of usability of electronic shopping: A heuristic evaluation", International Journal of Information Management, 25, 516-532, 2015.

[5] M. H. Hsiao, "Shopping mode choice: Physical store shopping versus e-shopping", Transportation Research Part E, 45, 86-95, 2009 .

[6] İnternet: Deloitte, Dijitalleşen Hayatımızda Mobil Teknolojilerin Yeri, Global Mobil Kullanıc1 Anketi 2017: Türkiye Yönetici Özeti, https:/www2.deloitte.com/content/dam/Deloitte/tr/Documents/tec hnology-media-telecommunications/deloitte_gmcs_2017.pdf, 24.10.2019

[7] G. Wagner, H. S. Klein, S. Steinmann, "Consumers' attitudes and intentions toward internet-enabled TV shopping", Journal of Retailing and Consumer Services, 278-286, 2017.

[8] S. M, Kuoppamäki, S. Taipale, T. A. Wilska, "The use of mobile technology for online shopping and entertainment among older adults in Finland", Telematics and Informatics, 34, 110-117, 2017.

[9] D. Cüceloğlu, İnsan ve Davranışı, İstanbul: Remzi Kitabevi, 1991.

[10] N. Turan, "Akış deneyimi üzerine genel bir literatür taraması", Pamukkale Üniversitesi Sosyal Bilimler Enstitüsü Dergisi, (37), 181-199, 2019.

[11] J. Nakamura, M. Csikszentmihalyi, "The concept of flow", Handbook of positive psychology, 89-105, 2002.

[12] M. Csikszentmihalyi, Beyond boredom and anxiety, San Francisco: Jossey-Bass, 1975.

[13] Y. K. Usluel, F. K. Vural, "Bilişsel Kapılma Ölçeği'nin Türkçeye Uyarlama Çalışması", Ankara Üniversitesi Eğitim Bilimleri Fakültesi Dergisi, 42(2), 77-92, 2009.

[14] D. Kim, Y. J. Ko, "The impact of virtual reality (VR) technology on sport spectators' flow experience and satisfaction", Computers in Human Behavior, 93, 346-356, 2019.

[15] S. Sanjamsai, D. Phukao, "Flow experience in computer game playing among Thai university students", Kasetsart Journal of Social Sciences, 39, 175-182, 2018.

[16] C.Ö. Fidanboy, "Çalışanların yaşam doyumuna yönelik algıları, örgütsel özdeşleşme düzeyleri ve akış deneyimi arasındaki ilişkiler: bilişim sektörü örneği”, OPUS Uluslararası Toplum Araştırmaları Dergisi, 12, 822-849, 2019.

[17] F. D. Davis, "Perceived usefulness, perceived ease of use, and user acceptance of information technology", MIS Quarterly, 13(3), 319$340,1989$. 
[18] T. Akçakanat, T. Erhan, H. Uzunbacak, "Meslek aşkının iş tatmini üzerine etkisi: akış deneyiminin aracı rolü”, IKCIIBFD, 2(1), 8095,2019

[19] M. Avcılar, G. Yenilmez, “Çok kanallı perakendecilik uygulamalarının algılanan deneyimsel değer ve akış deneyimi açısından karşılaştırılması", Osmaniye Korkut Ata Üniversitesi İktisadi ve İdari Bilimler Fakültesi Dergisi, 3(1), 137-114, 2019.

[20] I.-L.Wu, K.-W. Chen, M.-L. Chiu, "Defining key drivers of online impulse purchasing: A perspective of both impulse shoppers and system users", International Journal of Information Management, 36, 284-296, 2016

[21] C.-L. Hsu, H.-P. Lu, "Why do people play on-line games? An extended TAM with social influences and flow experience", Information and Management, 41, 853-868, 2004.

[22] L. C. Wang, D. F. Hsiao, "Antecedents of flow in retail store shopping", Journal of Retailing and Consumer Services, 19, 381 389,2012

[23] S. Yeke, E. Ceran, R. Pınar, "Teknoloji kabul modeli çerçevesinde çalışanların elektronik belge sistemini kullanmaya yönelik tutumu: kamu sektöründe bir uygulama", Kırklareli Üniversitesi Sosyal Bilimler Dergisi, 3, 159-168, 2019

[24] S. C. Yildırır, B. Kaplan, "Mobil uygulama kullanımının benimsenmesi: Teknoloji kabul modeli ile bir çalışma”, Kafkas Üniversitesi İktisadi ve İdari Bilimler Fakültesi Dergisi, 10(19), 22-51, 2019.

[25] S. Kalyoncuoğlu, "Tüketicilerin online alışverişlerindeki sanal kart kullanımlarının teknoloji kabul modeli ile incelenmesi”, Afyon Kocatepe Üniversitesi Sosyal Bilimler Dergisi, 20(2), 193-213, 2018.

[26] W. H. De Lone, E. R. Mclean, "Information Systems Success: The Quest for the Dependent Variable", Information Systems Research, 3(1), 60-95, 1992.

[27] S-J Hong, J. Y. L. Thong, K. Y. Tam, "Understanding continued information technology usage behavior: A comparison of three models in the context of mobile internet", Decision Support Systems, 42, 1819-1834, 2006.
[28] M. Kim, Y. Chang, M-C Park, J. Lee, "The effects of service interactivity on the satisfaction and the loyalty of smartphone users", Telematics and Informatics, 32, 949-960, 2015.

[29] Y. K Dwivedi, K. K. Kapoor, M. D. Williams, J. Williams, "RFID systems in libraries: An empirical examination of factors affecting system use and user satisfaction", International Journal of Information Management, 33, 367-377, 2013.

[30] T. Zhou, "An empirical examination of continuance intention of mobile payment services”, Decision Support Systems, 54, 1085$1091,2013$.

[31] M.-H. Hsu, C.-M. Chang, L.-W. Chuang, "Understanding the determinants of online repeat purchase intention and moderating role of habit: The case of online group-buying in Taiwan", International Journal of Information Management, 35, 45-56, 2015.

[32] H.-F. Lin, "Predicting consumer intentions to shop online: An empirical test of competing theories", Electronic Commerce Research and Applications, 6, 433-442, 2007.

[33] C. Yükselen, Pazarlama İlkeler, Yönetim, Örnek Olaylar (10. bs.), Ankara: Detay Yayıncılık, 2013.

[34] A. Ghasemi, S. Zahedias1, "Normality tests for statistical analysis: A guide for non-statisticians", International Journal of Endocrinology and Metabolism, 10(2), 486-489, 2012.

[35] E. Demir, Ö. Saatçioğlu, F. İmrol, "Uluslararası dergilerde yayımlanan eğitim araştırmalarının normallik varsayımları açısından incelenmesi”, Curr Res Educ, 2(3), 130-148, 2016.

[36] R. M. Baron, D. A. Kenny, "The moderator-mediator variable distinction in social psychological research: Conceptual, strategic, and statistical considerations", Journal of Personality \& Social Psychology, 51, 1173-1182, 1986.

[37] S. Sharma, R. M. Durand, O. Gurarie, "Identification and Analysis of Moderator Variables", Journal of Marketing Research, 18(3), 291-300, 1981. 